57 TIME IN REMISSION AND LOW DISEASE ACTIVITY STATE (LDAS) ARE ASSOCIATED WITH A BETTER QUALITY OF LIFE IN PATIENTS WITH SYSTEMIC LUPUS ERYTHEMATOSUS: DATA FROM A MULTI-ETHNIC, MULTICENTER US COHORT

${ }^{1}$ Manuel F Ugarte-Gil*, ${ }^{2}$ Guillermo J Pons-Estel, ${ }^{3}$ Luis M Vila, ${ }^{4}$ Gerald McGwin Jr, ${ }^{5}$ Graciela S Alarcón. 'Universidad Científica Del Sur; ${ }^{2}$ Grupo Oroño - Centro Regional de Enfermedades Autoinmunes y Reumáticas (GO-CREAR); ${ }^{3}$ Division of Rheumatology. University of Puerto Rico; ${ }^{4}$ School of Public Health. The University of Alabama at Birmingham; ${ }^{5}$ School of Medicine. The University of Alabama at Birmingham

\subsection{6/lupus-2019-|sm.57}

Background Achieving Remission and LDAS are desirable states in lupus patients as they are associated with better longterm outcomes including less damage accrual, lower flare rates and lower disease activity. However, whether achieving Remission and LDAS also account for a better quality of life (QoL) has not been examined. We hypothesized that this will be the case. The aim was to determine whether the proportion of time patients achieve either Remission or LDAS is associated with a better QoL.

Methods SLE patients from a well-established multiethnic, multicenter US cohort were included. Remission and LDAS were defined as follows: Remission, SLAM score $=0$ and prednisone $5 \mathrm{mg} /$ day and no immunosuppressants); LDAS not in remission, SLAM score 3, prednisone $7.5 \mathrm{mg} /$ day, no immunosuppressants; the proportion of time patients were in these two states (combined) was the independent variable. The endpoints were the physical and mental summary measures (PCS and MCS, respectively) and the individual subscales (Physical functioning: FP, Role Physical: RP, Bodily Pain: BP, General Health: GH, Vitality: VT, Social Functioning: SF, Role Emotional: RE and Mental Health: MH) of the Short Form (SF)36 at the last available visit. Linear regression was used to estimate the association between the proportion of follow-up time in remission and LDAS and the SF-36 measures with and without adjustment for the following baseline variables: age, gender, racial/ethnic group, education, poverty, social support, abnormal illness behaviors, fibromyalgia, disease activity, damage and the baseline scores of the corresponding SF-36 summary measures and subscales.

Results Five-hundred and forty-two patients with complete data for the dependent, independent and confounding variables were included. These patients were predominantly women, and either of Caucasian, African American or Hispanic ancestry. Overall, the mean scores for the summary measures of the SF-36 were low (38.9 for the PCS and 43.4 for the MCS); for the individual subscales the scores varied between 40.4 for VT and 65.4 for $\mathrm{MH}$. In the adjusted MV analysis, the percent of time on either Remission and LDAS was associated with better QoL after adjusting for potential confounders (table 1).

Conclusions The percent of time lupus patients stay on Remission or LDAS is associated with a better QoL as measured by summary measures and subscales of the SF-36.

Funding Source(s): None

\section{IDENTIFICATION OF SYSTEMIC LUPUS ERYTHEMATOSUS SUBGROUPS USING ELECTRONIC HEALTH RECORD AND GENETIC DATABASES}

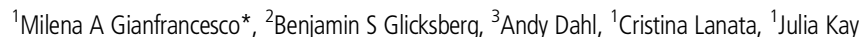
${ }^{1}$ Joanne Nititham, ${ }^{1}$ Kimberly Taylor, ${ }^{2}$ Ishan Paranjpe, ${ }^{3}$ Noah Zaitlen, ${ }^{2}$ Marina Sirota, ${ }^{1}$ Lindsey Criswell, ${ }^{4}$ Gabriela Schmajuk, ${ }^{5}$ Jinoos Yazdany. ${ }^{1}$ Division of Rheumatology, Department of Medicine, University of California, San Francisco; ${ }^{2}$ Baker Institute for Computational Health Sciences, University of California, San Francisco; ${ }^{3}$ Department of Neurology, University of California, Los Angeles; ${ }^{4}$ University of California, San Francisco; San Francisco VA Medical Center; ${ }^{5}$ UC San Francisco

\subsection{6/lupus-2019-Ism.58}

Background Systemic lupus erythematosus (SLE) is a multifactorial disease with genetic and environmental risk factors that encompass a wide range of disease severity and heterogeneous manifestations. Long-term outcomes for individual patients are difficult to predict and little is known about why an affected individual might develop a particular SLE phenotype. Identifying nuanced patterns in clinical and molecular data of patients could reveal distinct clusters of disease which could in turn lead to more refined and personalized treatment regimens. Previous studies have used phenotype-mapping approaches to identify subtypes of SLE using genome-wide association studies and gene expression data; however, no studies have integrated both genetic and clinical data from electronic health records (EHR) to identify SLE phenotypes using bioinformatic approaches.

\begin{tabular}{|c|c|c|c|c|c|}
\hline $\begin{array}{l}\text { SF- } \\
36^{*}\end{array}$ & $\begin{array}{c}\text { Number of } \\
\text { patients }\end{array}$ & Estimate & $\begin{array}{l}\text { Standard } \\
\text { error }\end{array}$ & $\begin{array}{c}t \\
\text { value }\end{array}$ & $p$ value \\
\hline MCS & 456 & 5.89 & 1.96 & 3.01 & 0.0027 \\
\hline PCS & 456 & 9.47 & 1.86 & 5.10 & $<0.0001$ \\
\hline FP & 472 & 18.14 & 4.85 & 3.74 & 0.0002 \\
\hline RP & 466 & 31.79 & 6.28 & 5.06 & $<0.0001$ \\
\hline BP & 469 & 19.97 & 4.91 & 4.07 & $<0.0001$ \\
\hline GH & 469 & 23.15 & 3.95 & 5.86 & $<0.0001$ \\
\hline VT & 472 & 13.39 & 4.03 & 3.32 & 0.0010 \\
\hline SF & 468 & 19.03 & 4.78 & 3.98 & $<0.0001$ \\
\hline RE & 463 & 26.28 & 6.37 & 4.13 & $<0.0001$ \\
\hline MH & 472 & 7.51 & 3.81 & 1.97 & 0.0495 \\
\hline
\end{tabular}

*Short Form-36. Mental Component Summary measure; Physical Component Summary measure; Physical functioning; Role Physical; Bodily Pain; General Health; Vitality; Social Functioning; Role Emotional; Mental Health Index. 